\title{
Neurophysiology of Magnocellular Forebrain Inputs to the Olfactory Bulb in the Rat: Frequency Potentiation of Field Potentials and Inhibition of Output Neurons
}

\author{
W. T. Nickell and M. T. Shipley \\ Department of Anatomy and Cell Biology, University of Cincinnati College of Medicine, Cincinnati, Ohio 45267
}

\begin{abstract}
Basal forebrain nuclei send projections, including cholinergic fibers, to forebrain cortical targets. These systems have been associated with several important functions, but their physiological actions are poorly understood. We have studied the neurophysiological characteristics of one of these systems, the projection from the nucleus of the horizontal limb of the diagonal band (HDB) to the main olfactory bulb (MOB) in the rat.

Single shocks to HDB produce modest field potentials in MOB with no detectable effect on the discharge characteristics of the principal output neurons of the MOB, the mitral cells. By contrast, continuous stimulation at $10 \mathrm{~Hz}$ for several seconds causes dramatic changes in the HDB field potential and mitral cell firing. During this period of stimulation, there is an initial facilitation of the field potential followed by a period of moderately reduced response amplitude that lasts a few seconds. This brief period of depression is succeeded by a sudden and marked potentiation of response amplitude and duration. This potentiated response can be maintained indefinitely by stimulation at lower frequencies than those required to initiate the potentiation effect. Coincident with the onset of the potentiated response, the spontaneous activity of the mitral cells is completely inhibited. Both the potentiation and mitral cell inhibition can be maintained indefinitely by continued stimulation at frequencies as low as $5 \mathrm{~Hz}$.
\end{abstract}

These observations demonstrate that magnocellular basal forebrain neurons exert powerful regulatory actions on specific neuronal populations in cortical targets.

At the time of their definition by Shute and Lewis (1967), the basal forebrain cholinergic neuronal systems were of relatively minor note to neurobiologists. Two recent lines of research have led to increased interest in these systems. In 1975, Kievit and Kuypers showed that some basal forebrain and hypothalamic cell groups project directly to the neocortex. Next, Mesulam and Van Hoesen (1976) demonstrated that many of the basal forebrain neurons which project to cortex contain AChE. Subse-

\footnotetext{
Received July 7, 1987; revised Mar. 21, 1988; accepted May 3, 1988.

We wish to thank Beata Frydel and Karen Wilburn for their histological work, Ying Tsai for assistance in preparation of figures, Steve Ziller for assistance with the experiments, and Sharon Harding for secretarial assistance.

This work was supported in part by the U.S. Army Medical Research and Development Command, Contract Numbers DAMD 17-86-C-6005 and DAMD 17-82-C-2272, and by NIH RO1 NS 20643-01.

Correspondence should be addressed to Dr. M. T. Shipley at the above address.

Copyright (C) 1988 Society for Neuroscience $0270-6474 / 88 / 124492-11 \$ 02.00 / 0$
}

quent studies using antibodies directed against choline acetyltransferase (ChAT) established that many of these cortical projecting basal forebrain neurons are cholinergic (Johnston et al., 1979; Mesulam et al., 1983a, b). It was also established that septal cholinergic neurons innervated the hippocampus (Mesulam et al., 1983a, b). The demonstration of cholinergic projections from nucleus basalis to neocortex was followed shortly by the discovery that these cholinergic neurons showed signs of selective degeneration or shrinkage in victims of Alzheimer's disease (Whitehouse et al., 1981, 1982; Coyle et al., 1983). These findings kindled great interest in the basal forebrain magnocellular systems.

It was initially supposed that the projection neurons in these nuclei were exclusively, or predominantly, cholinergic. Recent work, however, has demonstrated that many of the neurons which project to cortex do not express ChAT (Rye et al., 1984; Melander et al., 1985; Wainer et al., 1985). Many of the noncholinergic neurons contain GABA (Brashear et al., 1986; Zaborszky et al., 1986). Thus, the anatomical and neurochemical organization of these systems is more complex than originally thought.

The functional analysis of basal forebrain systems has lagged behind our understanding of their connections and chemoanatomy. This may be due, in part, to the anatomical complexity and cellular heterogeneity of the neocortex and hippocampus, the 2 major cortical targets of basal forebrain projections. In the present experiments we have studied some functional characteristics of basal forebrain inputs to a relatively simple cortical target, the olfactory bulb.

The basal forebrain projection to the olfactory bulb arises in the nucleus of the horizontal limb of the diagonal band (HDB). HDB is related anatomically, phylogenetically, and neurochemically to the magnocellular basal forebrain populations that innervate the neocortex and hippocampus (Price and Powell, 1970; Dennis and Keer, 1976; De Olmos et al., 1978; Macrides et al., 1981; Shipley and Adamek, 1984; Brashear et al., 1986; Zaborszky et al., 1986). Magnocellular neurons in HDB project to the olfactory bulb and secondary olfactory structures in all mammalian species examined. Compared with the neocortex and hippocampus, the anatomy (Macrides and Davis, 1983) and physiolngy (Shepherd, 1972) of the olfactory bulb are relatively simple and better understood. This greatly facilitates the interpretation of laminar field potential and single-unit response data.

Here, we report the effects of stimulating the nucleus of the diagonal band on synaptic field potentials and mitral cell discharge rates in the main olfactory bulb (MOB). The experiments show that single shocks to the HDB produce modest field po- 
tentials in the MOB but have little effect on ongoing mitral cell activity. However, brief epochs of maintained stimulation at physiologically relevant frequencies produce profound changes in the function of the MOB.

\section{Materials and Methods}

Male Sprague-Dawley rats, $250-400 \mathrm{gm}$, were anesthetized with chloral hydrate $(400 \mathrm{mg} / \mathrm{kg}$ supplemented as needed) or chloralose-urethane (30 $\mathrm{mg} / \mathrm{kg}$ chloralose, $1.5 \mathrm{gm} / \mathrm{kg}$ urethane). Essentially similar results were obtained with both anesthetics. Data reported here are based on experiments conducted in more than 100 animals.

The experimental set-up is illustrated schematically in Figure 1. Anesthetized animals were placed in a stereotaxic apparatus and the lateral aspect of the olfactory bulb and the lateral olfactory tract (LOT) were exposed by craniotomy after removing the contents of the orbit. A concentric bipolar stimulating electrode $(0.25 \mathrm{~mm}$ outer diameter, 0.75 $\mathrm{mm}$ tip separation; Rhodes Medical Instruments, Woodland Hills, CA) was guided stereotaxically into the nucleus of the HDB through a burr hole in the parietal bone. Stimulating currents werc delivered by a constant-current stimulus isolation unit. At the termination of each experiment, sufficient current was passed through this electrode to produce a lesion at the stimulation site; the location of the lesion was later determined in histological sections (Fig. 2).

Fibers from locus coeruleus and raphe nuclei traverse the region of the diagonal band; however, tract tracing studies suggest that most fibers from these brain-stem nuclei do not pass through the main body of HDB (McLean et al., 1986; McLean and Shipley, 1987); moreover, these fibers should have significantly higher activation thresholds than the large cell bodies in HDB. Stimulation currents were kept as low as possible to reduce the possibility of activating these axons; nevertheless, the possibility of some contribution from raphe or locus coeruleus fibers cannot be entirely excluded. The findings described here were obtained only when the stimulating electrode was centered in the HDB.

Glass capillary pipettes broken to approximately $5 \mu \mathrm{m}$ tip diameter and filled with $1 \mathrm{M} \mathrm{NaCl}$ were used for recording both field potentials and single units. In many experiments, 2 recording electrodes were used. One electrode was placed in the superficial part of the granule cell layer (gcl) and used to monitor changes in the amplitude of the field potential evoked by stimulation of the diagonal band, the second electrode was attached to a stepping-motor manipulator and used to record field and unit potentials at various depths in MOB. DC preamplification was used in all experiments. The amplified signal was usually bandpassfiltered between $0.1 \mathrm{~Hz}$ and $7.0 \mathrm{kHz}$, although in some cases DC coupling was used. For analysis of field potential response changes during long trains of HDB shocks, successive responses were digitized and stored in computer memory for later display and reproduction. Other responses were captured using a digital oscilloscope (Nicolet 4094), which allowed a sweep of several seconds to be stored, recalled, and analyzed. For analysis of single-unit responses, the signal was filtered to enhance spikes and processed through a window discriminator to derive an outpu suitable for computer processing. Poststimulus time histogram (PSTH) and firing rate (ratemeter) displays were constructed by computer (Motorola VME/10) and recorded for later analysis using programs developed in this laboratory.

A side-by-side bipolar stimulating electrode was placed against the LOT under visual guidance. Currents applied through this electrode were used for antidromic activation of the mitral cell axons, the principal output neurons of the olfactory bulb. Activation of LOT produces a characteristic potential that undergoes a change of polarity at the mitral cell body layer (Phillips et al., 1963); this transition is a precise indicator of electrode depth in the bulb. The depth of the recording electrode relative to the mitral cell body layer was determined during experiments by observation of the shape of the LOT-evoked potentials and by the presence of unit potentials at the mcl. In a few experiments, the electrode position was directly verified by iontophoretic deposits of HRP placed in the vicinity of the reversal point.

\section{Results}

Olfactory bulb responses to single shocks to $H D B$

Routinely, one recording electrode was advanced into the gcl of the main olfactory bulb before insertion of the stimulating electrode into HDB. This allowed optimal placement of the stimulation electrodes to be monitored by observation of the evoked field potential responses as a concentric bipolar stimulating electrode was lowered stereotaxically from the dorsal surface of the brain. In most penetrations, the path of the stimulating electrode intersected the posterior wing of the ispilateral anterior commissure (AC). Stimulation of this commissure resulted in a negative deflection recorded in $\mathrm{gcl}$. With further advancement of the stimulating electrode, this response declined in amplitude and disappeared. When the stimulating electrode was advanced further, into the $\mathrm{HDB}$, stimulation resulted in a characteristic biphasic potential in gcl, the HDB field potential.

In the gcl, the HDB potential (Fig. 3, bottom record, right column) consists of an initial positive-going phase (upward arrow in Fig. 3) followed by a slower negative-going wave (downward arrow in Fig. 3). The amplitude of the positive deflection $(\mathrm{P}+)$ varied greatly between preparations, and in some cases was absent. The latency of $(\mathrm{P}+)$ was always short $(4 \mathrm{msec}$ to the initial deflection, $6 \mathrm{msec}$ to the positive peak); this latency is consistent with the delay expected from axonal conduction over approximately $10-12 \mathrm{~mm}$ followed by a single synaptic delay. The negative deflection (P-), by contrast, is a much slower event, with the peak negativity at about $25 \mathrm{msec}$ latency. The exact beginning of $\mathrm{P}-$ was usually obscured by $\mathrm{P}+$ but always appeared to occur well after the beginning of $\mathrm{P}+$. In preparations in which $\mathrm{P}+$ was small or absent the initial negative deflection never occurred less than $8 \mathrm{msec}$ after the stimulus.

A response of similar time course but lower amplitude and opposite polarity is recorded superficial to the mitral cell layer (mcl). The reversal point for the response was approximately at the level of the mcl. This situation is reminiscent of the response to LOT stimulation (antidromic stimulation of mitral cells) (Phillips et al., 1963), and Figure 3 provides a comparison of LOT and HDB responses as a function of the depth of the recording electrode in the olfactory bulb. This record shows that the HDB potential reverses sign at approximately the same depth $(\mathrm{mcl})$ as the LOT potential.

\section{Potentiation of the $H D B$ response amplitude by $8-10 \mathrm{~Hz}$ stimulation of $H D B$}

We were unable to demonstrate significant effects of single shocks to $\mathrm{HDB}$ on the firing rate of neurons isolated in the MOB. Presumably, the synaptic currents produced by single shocks to HDB are not large enough to cause large changes in activity. However, the HDB field potential is markedly potentiated by several seconds of HDB stimulation at 8-10 $\mathrm{HZ}$. This potentiation of the HDB field potential appears to be accompanied by profound changes in function of MOB circuitry. It is quite probable that the HDB neurons may fire at this relatively low rate in the awake animal (see Discussion); hence, the behavior of the bulb after HDB potentiation probably represents a normal functional mode of the basal forebrain projection to the MOB. For this reason it was worthwhile to study the characteristics of this potentiation in some detail.

The effect of HDB potentiation on the HDB field potential is illustrated in Figure 4 , in which the HDB response before and $1 \mathrm{sec}$ after a $10 \mathrm{sec}$ period of $10 \mathrm{~Hz}$ stimulation of the HDB are superimposed. For this, and subsequent, field potential records, the recording electrode was in the gcl unless otherwise noted. By comparison with the first response, the negative phase of the potentiated response $\left(P_{-}\right)$is markedly increased in both amplitude and duration, while the initial positive phase $(\mathrm{P}+)$ is 


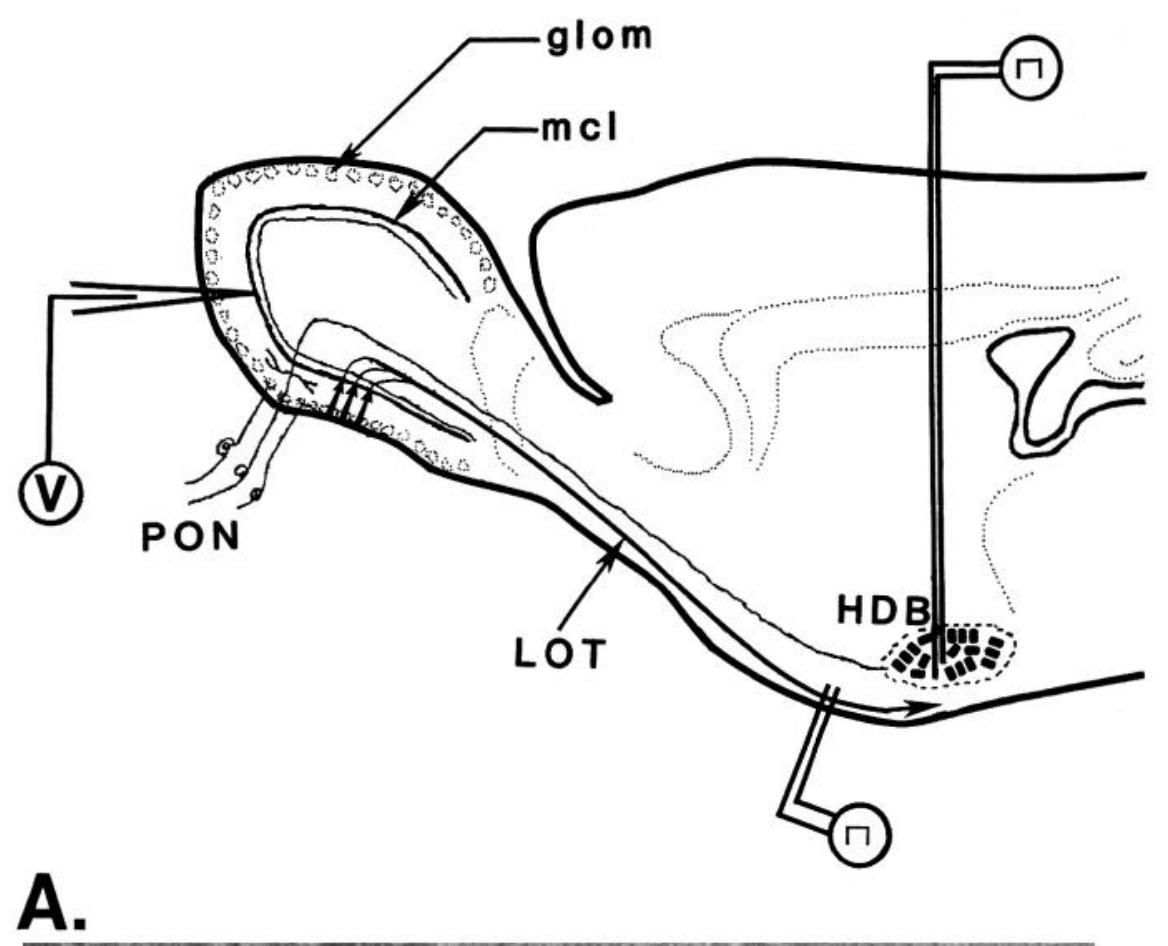

Figure 1. Schematic diagram of the experimental preparation. Abbreviations: glom, glomerular layer; $\mathrm{mcl}$, mitral cell body layer; $P O N$, primary olfactory nerve; $L O T$, lateral olfactory tract; $H D B$, horizontal limb of diagonal band.

Figure 2. Photomicrographs of coronal sections through the HDB. $A$, Bright-field micrograph of Nissl-stained section showing electrolytic lesion at stimulation site. $B$, Dark-field micrograph at approximately the same anterior-posterior level showing TMB reaction product following injection of the tracer WGA-HRP into the olfactory bulb. Abbreviations: $O C$, optic chiasm; $A C$, anterior commissure; $P C$, piriform cortex.

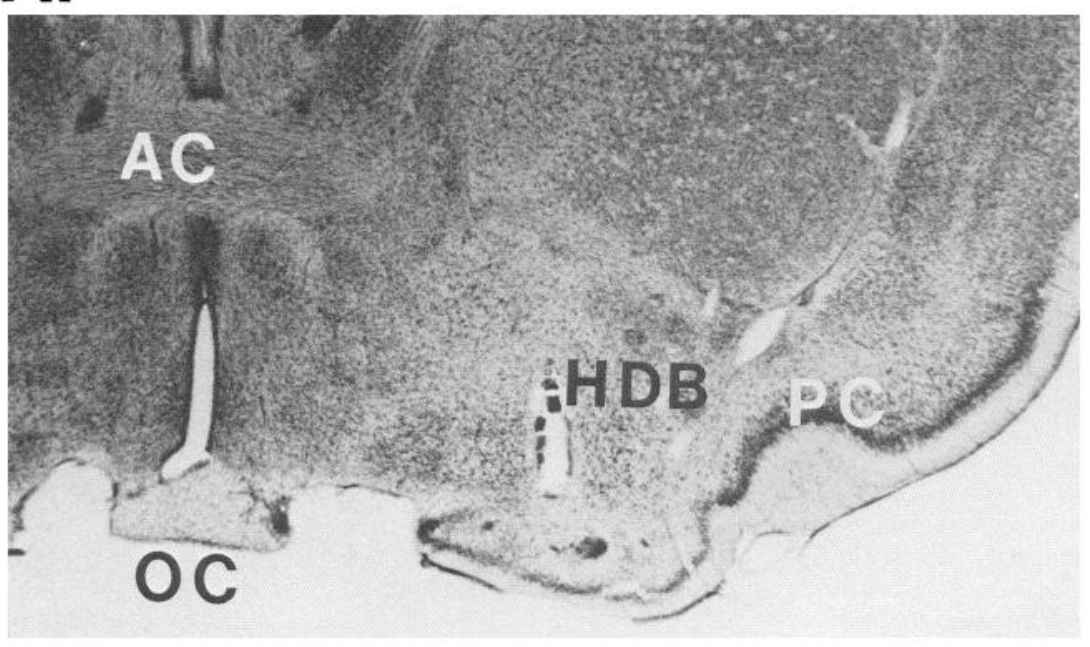

\section{B.}

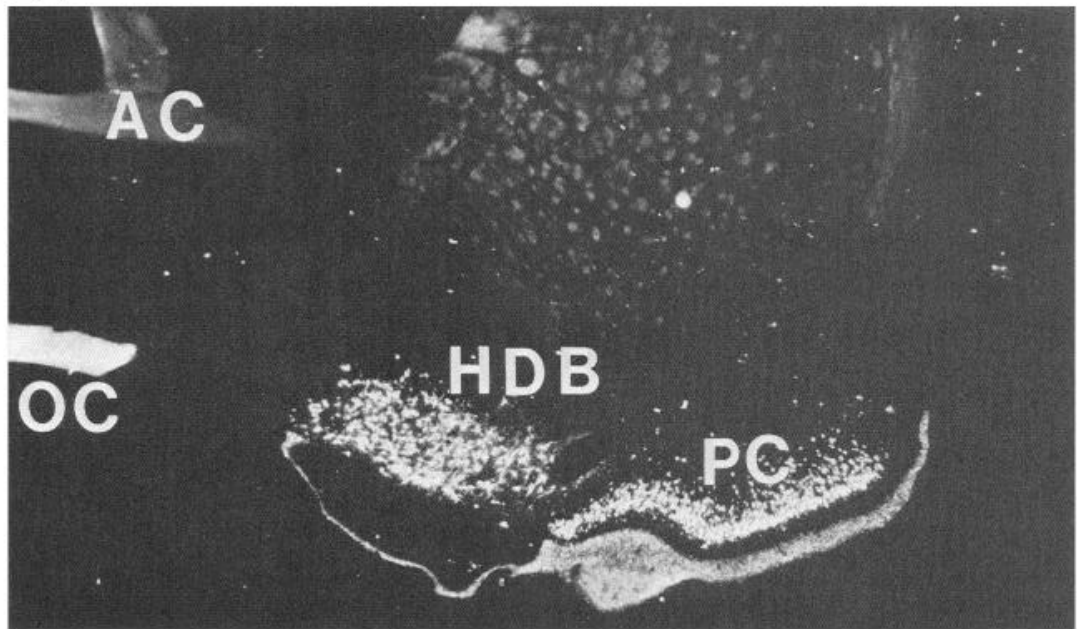




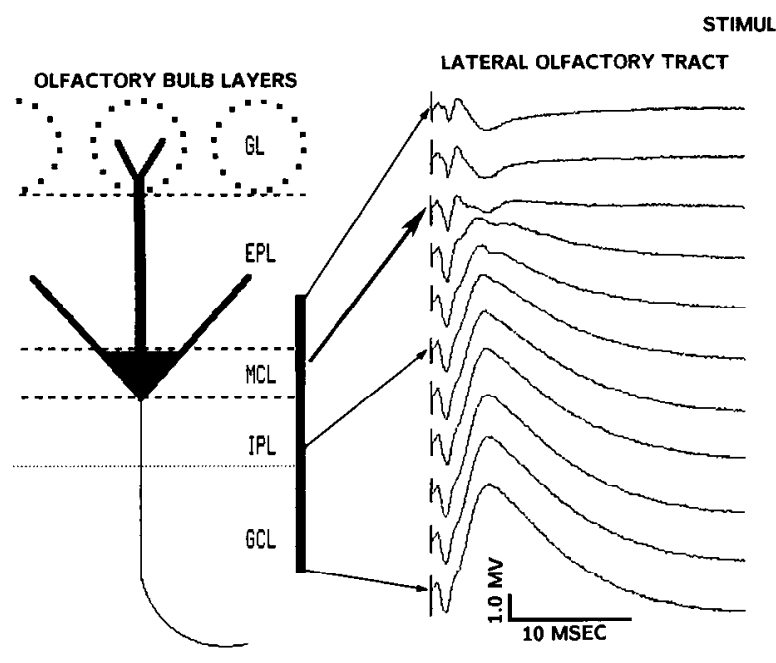

little changed. For convenience, we will sometimes refer to the potentiated negative deflection as the "potentiation wave." In the record presented, the amplitude of $P$ - is increased about 3.3 times, and the duration is markedly prolonged. Thus, the period of $10 \mathrm{~Hz} \mathrm{HDB}$ stimulation caused pronounced changes in the olfactory bulb that persisted for more than $1 \mathrm{sec}$ after the termination of the HDB stimulation.

\section{Development of potentiation of the HDB field potential}

During the potentiating stimulation, the field potential in the olfactory bulb typically undergoes a stereotyped series of changes. This is illustrated in Figure $5 A$, in which every fourth response of a train of 160 stimuli at $9 \mathrm{~Hz}$ was digitized and displayed. In this sequence there is an initial period of facilitation that is completely developed by the fourth response (second displayed sweep). In most cases, this initial period of facilitation lasts approximately $5 \mathrm{sec}$ and results in a significant increase in amplitude, with no change in shape of the response. After about 60 stimuli $(6.6 \mathrm{sec})$, the negative phase of the response decreases significantly in amplitude and remains relatively depressed for about 50 more stimuli $(5.5 \mathrm{sec})$. During this period of inhibition the time course of the response is also markedly prolonged.

After about 124 shocks (13.6 sec), in this case, the negative phase of the response, quite suddenly, undergoes an increase in amplitude and a change in shape (arrow, Fig. $5 A$ ). In Figure $5 B$ the amplitudes of the negative waves shown in Figure $5 A$ are plotted against time from the beginning of stimulation. The magnitude of the amplitude increase is variable between preparations; sometimes, the response does not grow beyond the amplitude of the initial facilitated response, but typically the response undergoes a 2 -fold or greater increase in amplitude over the initial facilitation. The constant features are the changes in shape of the response and the DC shifts that occur at this point.

\section{$D C$ shifts during HDB potentiation}

During the course of the potentiating stimulation, there are also shifts in DC level that correspond to the changes in shape of the response described above. This is illustrated in Figure 6, which is an oscilloscope trace taken at slow sweep speed during HDB stimulation at $8.3 \mathrm{~Hz}$ (different preparation than Fig. 5). The record was acquired using a digital oscilloscope so that it was possible to expand the sweep and examine the waveform

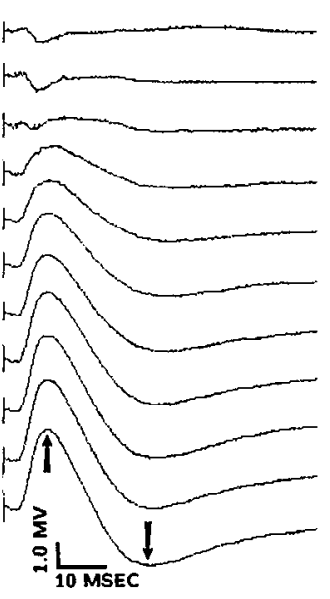

Figure 3. Comparison of $\mathrm{HDB}$ and LOT potentials as a function of recording electrode depth. The right column represents the results of HDB stimulation; the left, LOT stimulation. Beginning about $300 \mu \mathrm{m}$ below the surface of $\mathrm{MOB}$, the recording electrode was advanced $50 \mu \mathrm{m}$ before each pair of sweeps. The mitral cell body layer $(m c l)$ is located at the point where the LOT potential changes polarity (heavy arrow). As with the LOT potential, the HDB potential changes sign at the mcl. Note the difference in the sweep rate between the 2 records. Abbreviations: $G L$, glomerular layer; $E P I$, external plexiform layer; $M C L$, mitral cell layer; $I P L$, internal plexiform layer; $G C L$, granule cell layer. of individual responses at critical points during the potentiation. The beginning of the slow negative DC shift $(a)$ corresponds to the broadening and relative inhibition of the negative deflection seen in Figure 5 at about $5 \mathrm{sec}$ stimulation. The point at which the slow negative deflection stops and the width of the trace increases $(b)$ corresponds to the sudden onset of potentiation of Figure $5 A$.

A single test shock to HDB given 1 sec after the termination of the potentiating train is shown at $c$ in Figure 6. The amplitude of this deflection is substantially larger than either the control response or the potentiated responses during the stimulating train. The response amplitude, however, reaches about the same $\mathrm{DC}$ level as the potentiated responses recorded during $10 \mathrm{~Hz}$ stimulation. The deflections on either side of the HDB shock are spontaneously occurring waves, which are described in more detail later.

\section{Duration of the potentiated state}

Maximum amplitude of the potentiation wave occurred when the HDB test stimulus was given about $1 \mathrm{sec}$ after termination of the potentiating shocks. By $3 \mathrm{sec}$ after termination of the potentiating stimulation, the potentiation had decayed, and the HDB response was back to control amplitude. The time course of decay of potentiation was further defined by measuring the amplitudes of the response (maximum negative deflection) to single test shocks delivered at different times after termination

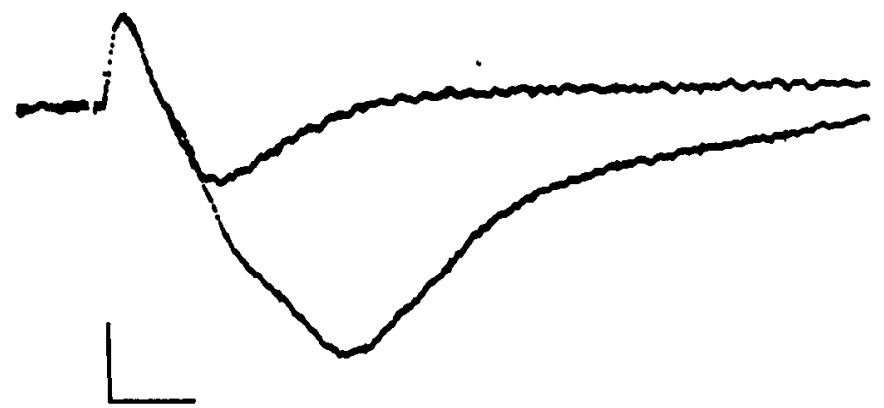

Figure 4. Comparison of normal and potentiated DB potential. The recording electrode is in the granule cell layer. Two records are superimposed. Smaller trace, Single shock to diagonal band; larger trace, same stimulus $1 \mathrm{sec}$ after a period of HDB stimulation at $10 \mathrm{~Hz}$. Calibration marker: $40 \mathrm{msec}, 0.5 \mathrm{mV}$. 

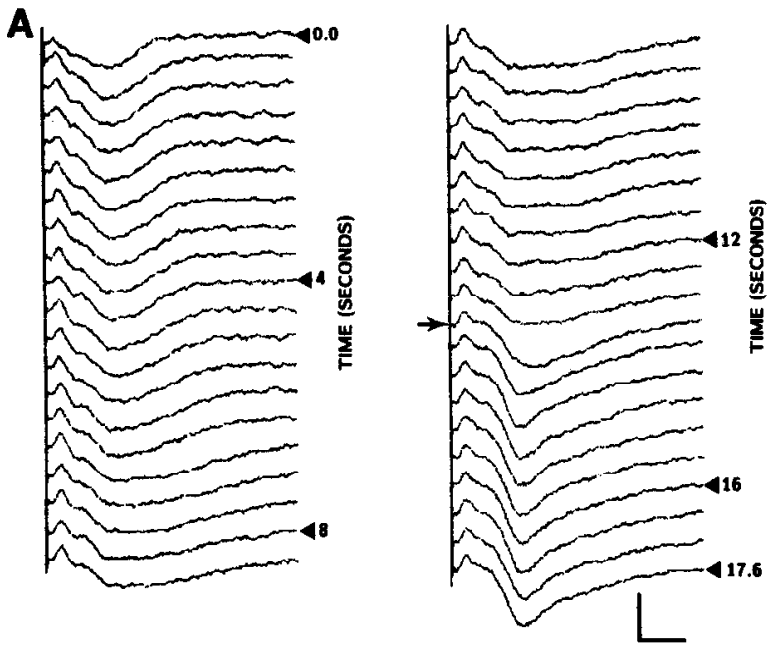

B

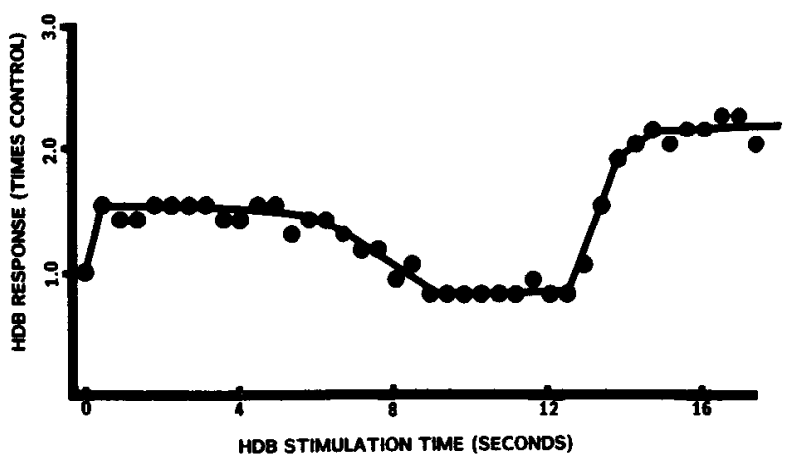

Figure 5. Time course of development of the potentiation effect. HDB was stimulated at $9 \mathrm{~Hz}(110 \mathrm{msec}$ interval $)$ for a total of 160 stimuli. $A$, Every fourth response was digitized, stored in computer memory, and then plotted with baseline shift removed. Calibration marker: 20 msec, $0.5 \mathrm{mV}$. $B$, Amplitudes of the negative deflection in the record above plotted against stimulation time.

of the potentiating train. Before each test pulse, the preparation was stimulated with an identical train of 160 shocks to HDB. Ten minutes rest was allowed between each potentiation trial. The result of a typical experiment is presented in Figure 7, in which the amplitude of the negative deflection $(\mathrm{P}-)$ is plotted against time from termination of the potentiating train. The response amplitude increases for the first $500 \mathrm{msec}$, remains constant another $500 \mathrm{msec}$, and then decays to half-amplitude by about $2 \mathrm{sec}$ after termination of the potentiating train; the

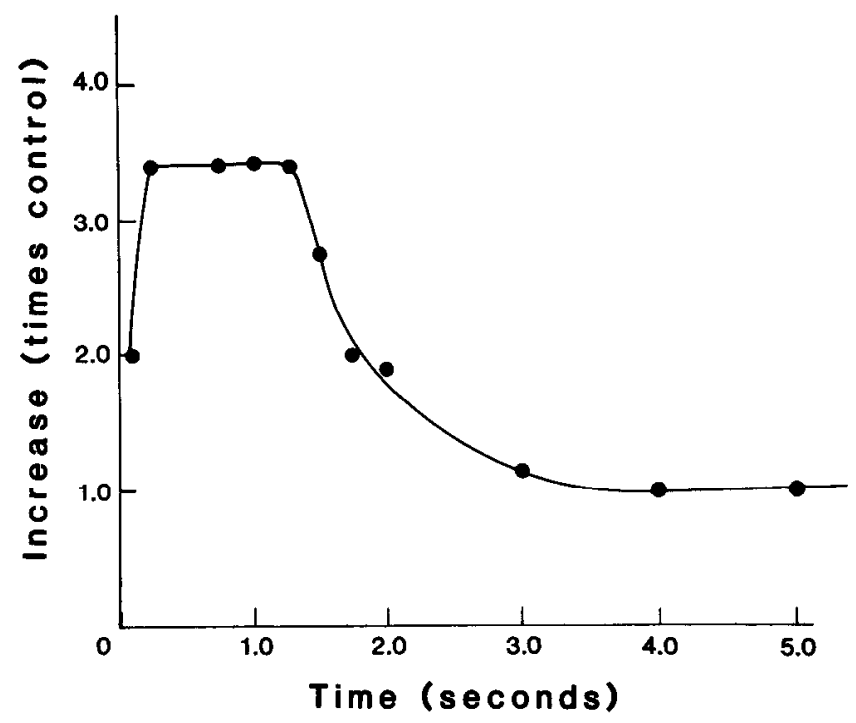

Figure 7. Time course of potentiation after termination of the stimulating train. Single shocks to $\mathrm{HDB}$ were given at selected intervals after termination of identical trains of 160 shocks given to HDB. Ten minutes rest was allowed between each trial.

response returns to control values after about $3 \mathrm{sec}$. Thus, potentiation caused by the period of HDB stimulation lasts less than $3 \mathrm{sec}$.

\section{Characteristics of the potentiated state}

Figure $8 A$ shows the response to trains of $\mathrm{HDB}$ shocks given at $300 \mathrm{msec}$ intervals before (top trace) and after (bottom trace) HDB potentiation. Before potentiation, the approximately $3 \mathrm{~Hz}$ stimulation results in a small field potential, which does not change with continued stimulation. The lower trace in Figure $8 A$ shows the response to an identical series of HDB shocks beginning $1 \mathrm{sec}$ after termination of a potentiating train to HDB. After $\mathrm{HDB}$ potentiation, the negative deflections $(\mathrm{P}-)$ are strongly potentiated (5-6 times control values; Fig. 8, $A$ and $B i i$ ). After the first response (Fig. $8 A$ ), there are additional spontaneous deflections. Although the spontaneous deflections are not repeated, the amplitude of the potentiated responses is maintained without decrement during the period of stimulation (the last response is $2200 \mathrm{msec}$ after termination of the HDB potentiating train). Thus, $3 \mathrm{~Hz}$ stimulation extended the duration of potentiation beyond that measured by single test shocks.

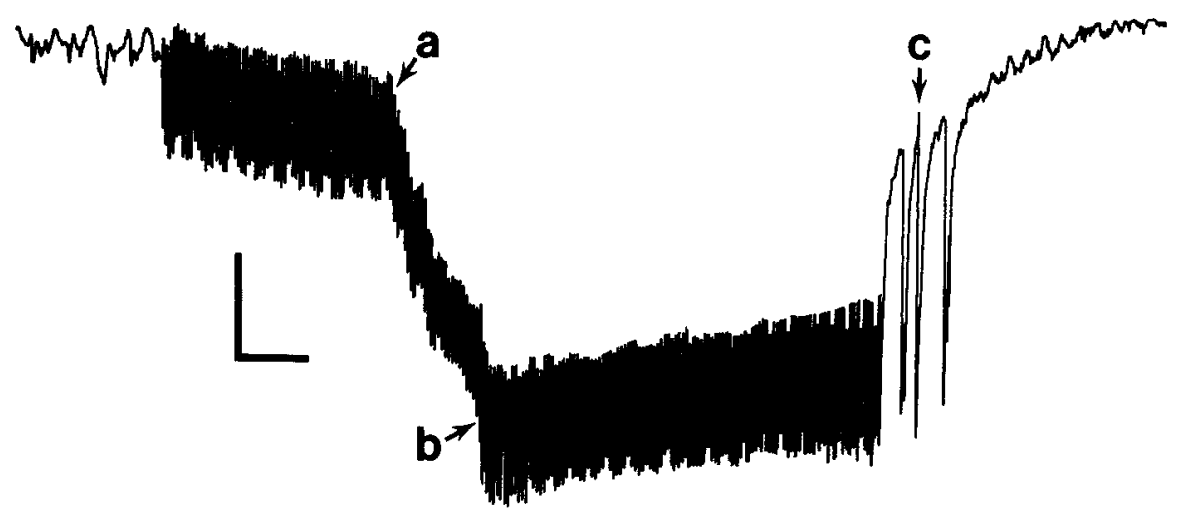


A

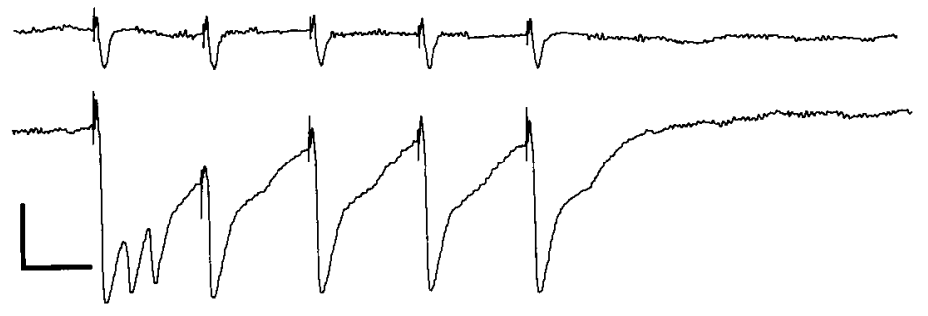

B
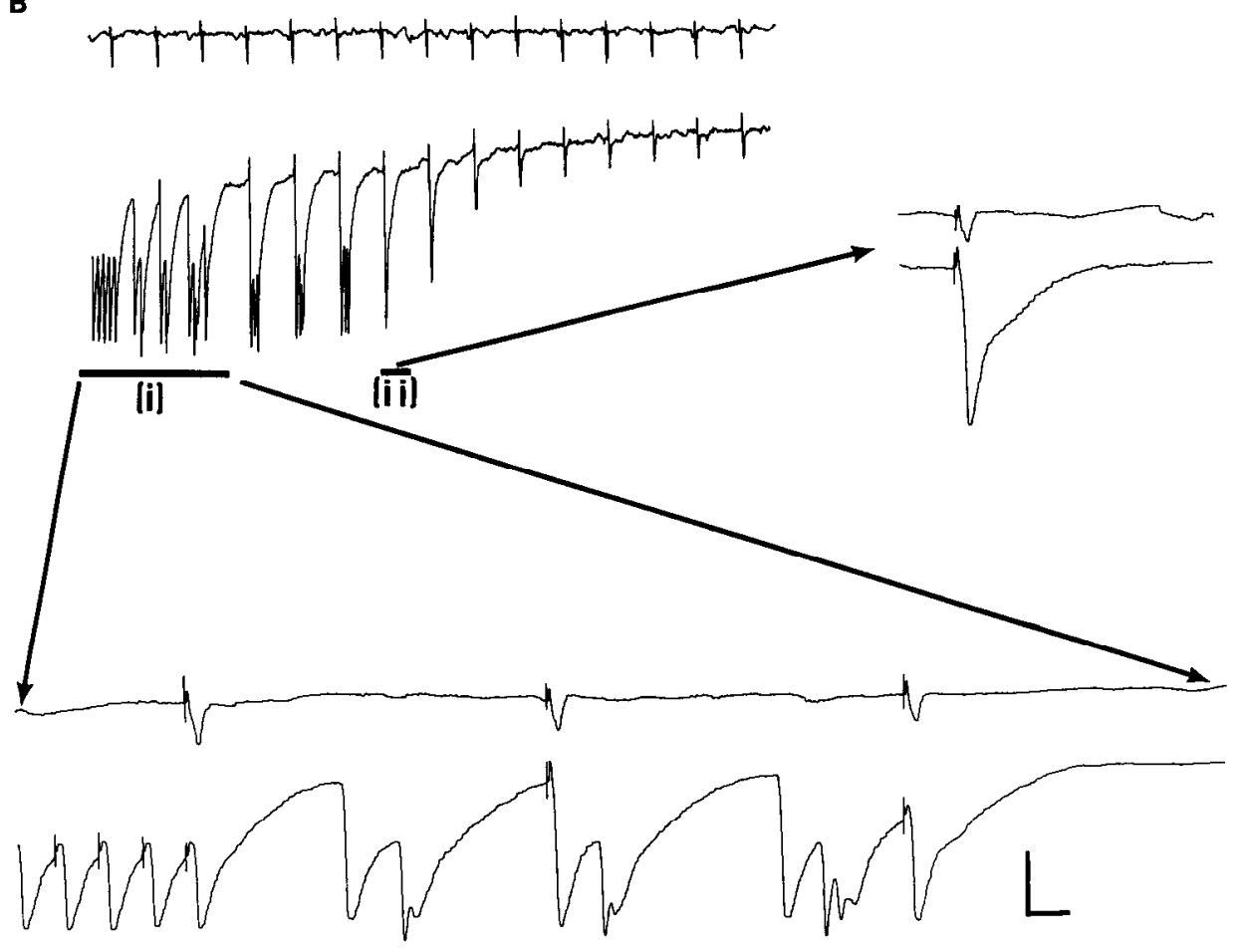

Figure 8. Responses in the olfactory bulb after HDB potentiation. In each record the top trace is a control record without previous HDB stimulation and the lower trace is the response after HDB potentiation. DC coupling was used. $A$, Five test shocks to HDB at $300 \mathrm{msec}$ interval. First shock is $1.0 \mathrm{sec}$ after termination of HDB potentiation train. $B$, Termination of a train of HDB shocks (13 sec at $8.3 \mathrm{~Hz}$ ) followed by a train of HDB shocks at $1 \mathrm{~Hz}$ intervals. Insets, Portions of the 2 traces indicated by horizontal bars expanded 8 times in the time axis. Calibration marker: $A, 200$ msec and $250 \mu \mathrm{V} ; B, 1.0 \mathrm{sec}$ and 250 $\mu \mathrm{V}$ for the main figure; $125 \mathrm{msec}$ and $250 \mu \mathrm{V}$ for the insets.
Figure $8 B$ shows the response to a train of shocks given at 1 sec intervals before (top trace) and after (bottom trace) HDB potentiation. The record also shows the responses to the final 5 shocks of the potentiating train. Several aspects of the HDB potentiation are demonstrated in this record. As shown in Figures $6,8 A$, the HDB test responses are substantially larger than those occurring during the potentiating train although both test and potentiating responses reach approximately the same DC level (Fig. $8 B i$ ). The first driven response ( $1 \mathrm{sec}$ after the potentiating train) is preceded and followed by spontaneously occurring waves of similar amplitude and time course. The responses to $1 \mathrm{~Hz} \mathrm{HDB}$ test shocks are unchanged for the first 5 test shocks and then fall to about half-amplitude at the 8th test shock. Thus, even with test shocks given to HDB at $1 \mathrm{sec}$ intervals the potentiated state lasts substantially longer than when the duration of potentiation is tested with single shocks (Fig. 7). As with the onset of potentiation, the decay, once begun, is quite rapid.

The HDB stimulation frequency required to produce potentiation in a particular preparation ranged between 8 and $12 \mathrm{~Hz}$. The lowest frequency found to produce potentiation was $6 \mathrm{~Hz}$.
After potentiation was induced, however, lower frequencies would maintain it. In most preparations, repeated stimulation at $5 \mathrm{~Hz}$ after potentiation was achieved would maintain the potentiated state indefinitely.

Very similar results were obtained with either of the anesthetics (chloral hydrate and chloralose-urethane) used. Quantitative parameters, such as the number of stimulation shocks required to generate potentiation and the duration of the potentiated state, appeared to vary with the level of anesthetic and between preparations. However, the qualitative features of the phenomenon were entirely reproducible.

\section{Effect of $H D B$ stimulation on the activity of output neurons}

The potentiation wave may involve the direct or indirect synaptic excitation of granule cells. It is important to confirm this directly by single-unit recordings; however, granule cells do not appear to be spontaneously active under the anesthetic conditions used in the present experiments. We were unable to find spontaneously active units when the recording electrode was in gcl. The mitral cells, however, are intimately linked to the granule cells through reciprocal dendrodendritic synapses in the ex- 

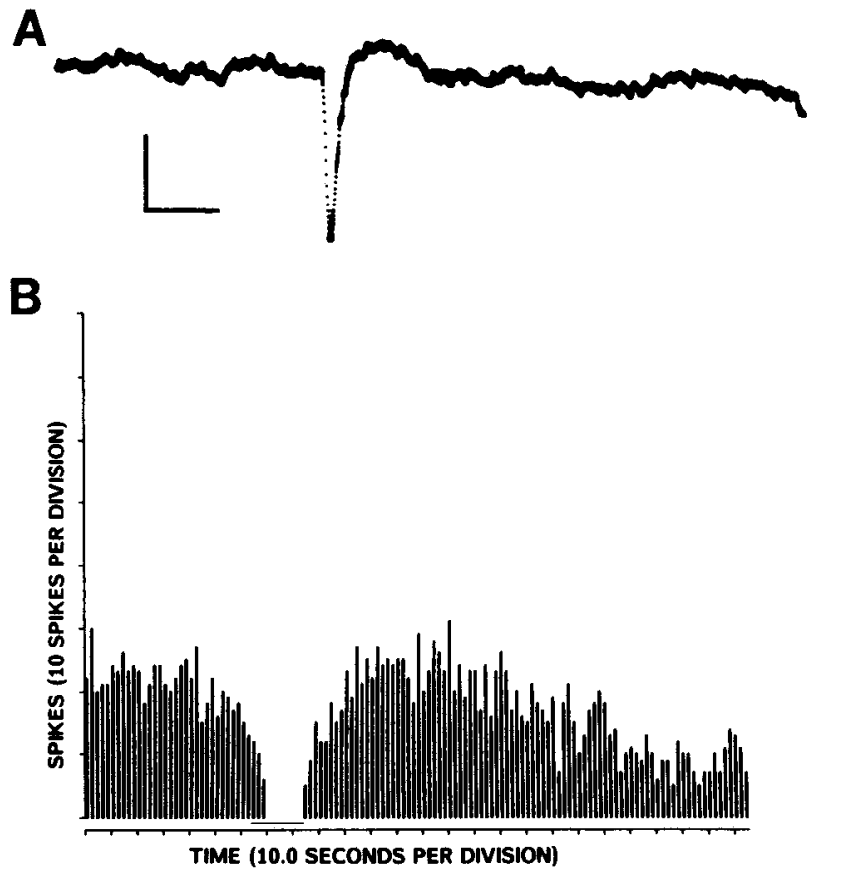

Figure 9. A, Extracellularly recorded waveform of typical mitral cell unfiltered record. $B$. Firing rate of a presumed mitral cell before and during a period of stimulation of the diagonal band at $10 \mathrm{~Hz}$. $\mathrm{HDB}$ was stimulated at $10 \mathrm{~Hz}$ during the period indicated by the horizontal bar beneath the record. Firing rate of the cell was not affected during the initial period of HDB stimulation, but with the onset of potentiation the cell stops firing. At termination of HDB stimulation, the cell resumes firing. Calibration marker: $2.0 \mathrm{msec}, 0.5 \mathrm{mV}$.

ternal plexiform layer (epl) (Rall and Shepherd, 1968; Mori and Takagi, 1978b). Thus, the behavior of mitral cclls can be used as an indicator of granule cell activation.

The mcl was identified by the turnover of the LOT potential, and by the presence of a background of activity heard through the acoustic monitor as the layer was approached. When the recording electrode was in this region, clearly defined units could be isolated easily (Fig. 9A). These waveforms were usually stable for extended periods. In some experiments, recordings were made using electrodes filled with $1 \% \mathrm{HRP}$ in $0.9 \% \mathrm{NaCl}$. Deposits of HRP were made iontophoretically, and their location was histologically verified after reaction with diaminobenzidine (DAB). In all cases the locations of the reaction deposits corresponded to the expected location of the recording electrode.

Deep to the mcl there are several classes of interneuron (Schneider and Macrides, 1978). Except for the granule cells, which are not spontaneously active (Nakashima et al., 1978; Mori and Takagi, 1978a), these interneurons are not numerous. Thus, it is improbable that we recorded consistently and selectively from any of the interneurons below mcl. The cell bodies of internal tufted cells lic close to $\mathrm{mcl}$, and an electrode lying near the superficial surface of mcl might record from one of these neurons. With our preparation, it would not be possible to distinguish internal tufted from mitral cells, since the former cells send axons out the LOT (Scott, 1981; Kishi et al., 1984). In the rat, however, internal tufted cells appear to be rare (Scott, 1981; Orono et al., 1984). All units in the vicinity of mcl which could be effectively isolated behaved in a similar manner to HDB stimulation; thus, it is likely that the extracellular unit
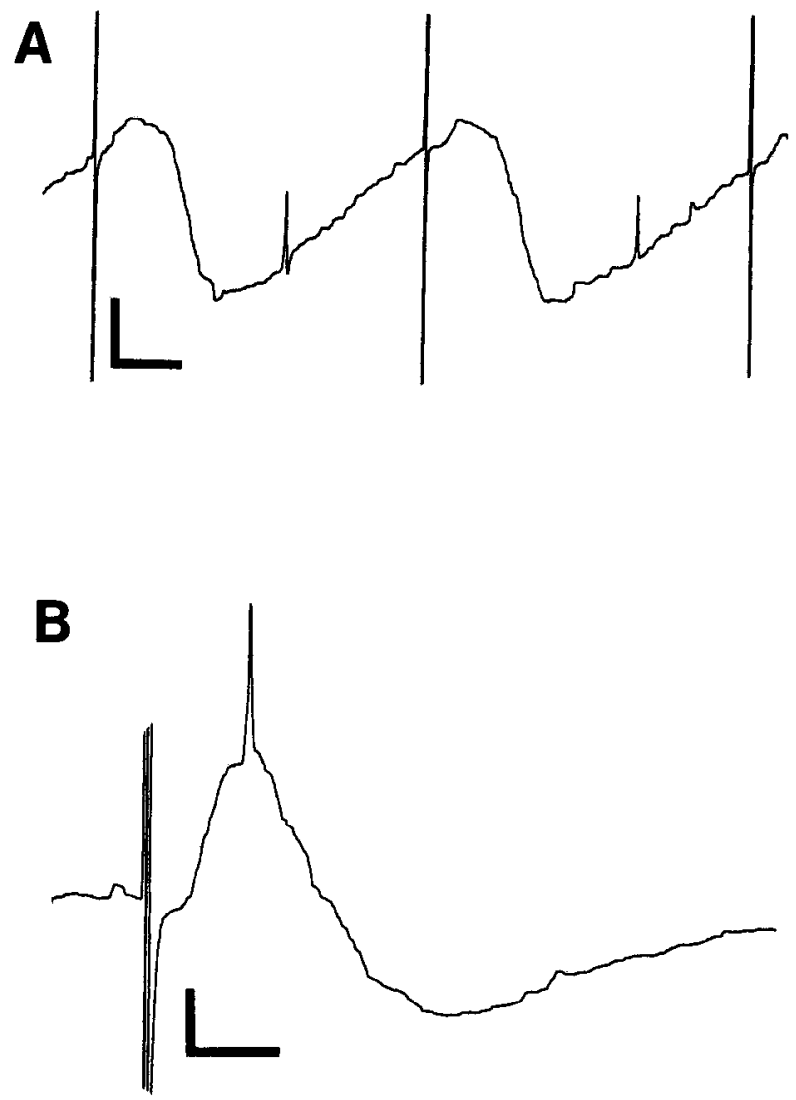

Figure 10. Single-unit recordings of neurons active during HDB stimulation. Both records are unfiltered. $A$, Neuron located in gcl $320 \mu \mathrm{m}$ deep to $\mathrm{mcl}$ that was active only after HDB stimulation. Two responses are shown. $B$, Neuron located $177 \mu \mathrm{m}$ below $\mathrm{mcl}$. This neuron fired spontancously in bursts of 3 spikes at a very low rate. Following HDB potentiation, the neuron's firing became synchronized with the positive phase of the HDB field potential. Calibration markers: $A, 1.0 \mathrm{mV}, 20$ $\mathrm{msec} ; B, 1.0 \mathrm{mV}, 10 \mathrm{msec}$.

responses described below represent firing of mitral cells. A total of 30 presumed mitral cells were studied.

We were unable to demonstrate any effect of single shocks to $\mathrm{HDB}$ on presumed mitral cell firing rate: $\mathrm{PSTH}$ records of mitral cell firing following single shocks to HDB did not reveal any pattern of excitation or inhibition following the HDB shock. By contrast, during potentiation of the HDB field potential there is a dramatic change in mitral cell spontaneous discharge rate.

The results of a typical experiment are shown in Figure 9, which is a record of the spontaneous firing of a mitral cell. At the beginning of HDB stimulation (indicated by the horizontal line beneath the record), the firing rate of the cell is minimally affected. After a few seconds of stimulation, however, the cell ceases to discharge. This occurs at the same time as the onset of potentiation of the HDB field potential. The cell remains completely inhibited throughout the period of HDB stimulation. In many cases, as in the present record, there is a rebound of mitral cell firing above the control rate following termination of HDB stimulation. This rebound can last for more than 30 sec. Potentiation of the HDB response always caused inhibition of presumed mitral cell spontaneous firing. In no case were these cells excited by HDB potentiation. The effect of HDB stimulation on odorant-induced mitral cell activity was not investi- 
gated, nor have we systematically examined the action of HDB on tufted cell firing rates.

\section{Other classes of cells}

In the gcl, spontaneously active units were never found. However, during potentiation it was occasionally possible to find cells in gcl that discharged during the $\mathrm{P}-$ phase of the HDB potential. To isolate these cells, HDB potentiation was induced by stimulation at $10 \mathrm{~Hz}$. The stimulation frequency was then decreased to $5 \mathrm{~Hz}$ or less to maintain potentiation and the recording electrode advanced in $5 \mu \mathrm{m}$ steps until an action potential was detected. Once isolated, the units exhibited quite stable behavior, firing during the $\mathrm{P}$ - phase of the HDB potential (Fig. 10A). Firing of these units was very closely linked to potentiation; if test $\mathrm{HDB}$ pulses are given after a potentiating series, these inframitral units disappear at the same time as the potentiation. We tentatively interpret these units as granule cells that are driven to produce spikes by the HDB potentiation wave. Granule cells have been previously reported to produce spikes under certain physiological conditions after stimulation of LOT (Nakashima et al., 1978). Because of the difficulty of isolating these normally silent neurons, we have not yet conducted a thorough study of their physiological characteristics; 6 of these neurons that discharged only during HDB potentiation were isolated in the course of these experiments.

In 2 cases, a second type cell was isolated about $150 \mu \mathrm{m}$ deep to the turnover of the LOT potential. In the resting preparation these cells fired at low frequency in bursts of about 3 spikes. Following HDB potentiation, the firing of these cells became synchronized with the positive phase of the HDB potential $(\mathrm{P}+)$ (Fig. 10B). These neurons are presumably located in the inner plexiform layer (ipl), which is a region receiving strong input from $\mathrm{HDB}$; it is also the location of a class of interneurons that produce AChE, but not ChAT (Nickell and Shipley, 1988). The relative difficulty of isolating these cells is consistent with the hypothesis that they are members of a relatively small population of interneurons.

\section{Discussion}

Stimulation of basal forebrain neurons in the HDB causes several effects in the MOB. Single shocks produce a field potential of modest magnitude that facilitates with short trains of shocks. Using single or short trains of shocks it is difficult to find effects that suggest possiblc functions of the system. The functional significance of this magnocellular projection becomes more apparent, however, when stimulation is continued for several seconds. Thus, in addition to the initial brief facilitation there are slowly developing changes in bulb synapses that are only revealed by several seconds of stimulation at $8-10 \mathrm{~Hz}$. In the anesthetized animal, a stimulation rate of $8-10 \mathrm{~Hz}$ is sufficient to initiate these effects; once they are activated, continued stimulation at rates below $5 \mathrm{~Hz}$ will maintain them.

\section{Depth profile analysis}

The relatively simple, laminated, cortical structure of the olfactory bulb and its physiological characterization by previous investigators (Shepherd, 1972) allow reasonable inferences to be made about the location and targets of activated synapses from depth profile analysis of the HDB field potentials. Since the depth profile of the HDB field potential is similar to that of the LOT potential, we will assume that the classical analysis of the LOT potential developed by Rall and Shepherd (1968) can be applied to the HDB potential.

The initial positive peak of the HDB response recorded in gcl $(\mathrm{P}+)$ is of interest because stimulation of most centrifugal inputs to the olfactory bulb produces a negative field potential in $\mathrm{gcl}$, presumably as a result of excitatory synapses onto granule cells in gcl (Nakashima et al., 1978). As with the positive third phase of the LOT potential, the initial positive HDB peak could result either from an excitatory input onto dendrites in the epl of neurons whose cell bodies are deep to the mcl (i.e., in the ipl or $\mathrm{gcl}$ ) or, alternatively, from an inhibitory input onto granule cells or their dendrites in the gcl. Following the analysis of Rall and Shepherd (1968), it is more probable that $\mathrm{P}+$ results from excitatory processes, since inhibitory conductances have equilibrium potentials near the resting potential and for this reason do not usually generate sufficient extracellular current to produce significant field potentials. Thus, the positive HDB peak recorded in gcl is interpreted as an excitatory termination of HDB fibers onto dendrites in epl of interneurons whose cell bodies are below the mcl. This is in accord with anatomical observations that fibers from HDB terminate in the epl (Macrides et al., 1981; Shipley et al., 1986).

The negative deflection of the HDB potential $(\mathrm{P}-)$ represents either an inhibitory input to the granule cell dendrites in the epl or an excitatory input to granule cell dendrites in the gcl. By the same reasoning used for the $\mathrm{P}+$ potential (i.e., that an inhibitory input usually does not generate a significant field potential), an excitatory input is more plausible. This excitatory input could result from either (1) a second direct input from HDB terminating in gcl or (2) an indirect activation of granule cells mediated by an excitatory interneuron. The latency of the positive $(\mathrm{P}+)$ potential is short and consistent with monosynaptic activation, but the negative deflection begins after a longer delay. Thus, the characteristics of the negative deflection are more consistent with the second alternative, i.e., HDB activation of an excitatory interneuron that synaptically activates granule cells.

The hypothesis of an intermediate excitatory interneuron also provides a plausible explanation of the sudden onset of the potentiation wave and its apparent spontaneous repetition. The increase in response amplitude might reflect either an increase in transmitter released by terminals from HDB or an increase in responsiveness of the postsynaptic elements. There are reported examples of both kinds of mechanisms, but such changes usually develop gradually, unlike the sudden onset of the HDB potentiation wave. A gradually developing facilitation could, however, cause a sudden potentiation of the HDB field potential if it resulted in the initiation of spike discharges when threshold is reached in the proposed interneuron. This would result in increased release of transmitter from interneuron terminals onto granule cells, accounting for the observed increase in response amplitude in the potentiation wave. Maintained firing of these excitatory interneurons for a period after the termination of HDB stimulation would also account for the spontaneous repetitions of the potentiation wave.

If the hypothesized excitatory interneuron does exist, then it would have to correspond with one of the less numerous classes of interneurons that have been described in the olfactory bulb (Schneider and Macrides, 1978). Such a class of interneurons might serve to amplify the relatively sparse HDB input if each of the interneurons contacts numerous granule cells. Although too few cells were found to warrant firm conclusions, the units recorded just below the mcl exhibit the temporal characteristics 
expected of the hypothesized interneuron. The fact that these neurons were rarely encountered is consistent with the idea that they represent a small population.

We have recently (Nickell and Shipley, 1988) described a population of interneurons located below the mcl in the ipl and the superficial part of the gcl, which express AChE but not ChAT. These neurons are appreciably larger than granule cells and appear to send processes both superficially into the epl and deeper in to the gcl. These large interneurons are good candidates to receive input from HDB and to produce an excitatory input onto the deep dendrites of granule cells. Thus, the negative HDB response may be mediated by a class of large, AChE-positive excitatory intcrncurons localized primarily in the ipl, with dendrites that extend into the deep part of the epl and into the gcl.

The DC shift during HDB potentiation appears to be caused by the prolongation of the time course of the negative wave $(\mathrm{P}-)$ that occurs after a few seconds of HDB stimulation. The duration of this field potential is probably similar to the duration of the underlying excitatory synaptic current in the granule cells. When the duration of this current exceeds the interval between the stimulation shocks the currents will summate, leading to the DC shift. Summation of the currents would also result in progressive depolarization of the granule cells; they might eventually be depolarized to a level sufficient to produce spikes (Mori and Takagi, 1978b; Nakashima et al., 1978). The onset of spiking in the granule cells would probably result in sharply increased inhibitory transmitter release from granule cell terminals. If some of the granule cell processes synapse upon the hypothetical excitatory interneurons, then this incrcased inhibitory transmitter release would create inhibitory currents in the excitatory interneurons. These inhibitory currents would limit any further increase in transmitter release. The sudden termination of the downward deflection in the DC coupled record ( $b$ in Fig. 6) might result from the activation of this negativefeedback mechanism.

\section{Inhibition of mitral cells by HDB stimulation}

The inhibition of mitral cell spontaneous firing during HDB stimulation is also consistent with the hypothesis that the HDB response leads either directly or through an excitatory interneuron to the activation of granule cells. Centrifugal inputs from anterior commissure and the ipsilateral piriform cortex terminate predominantly in the gcl (Davis and Macrides, 1981), and stimulation of these inputs causes excitatory potentials in granule cells (Nakashima et al., 1978). Antidromic activation of mitral cells through stimulation of the LOT results in excitatory input to granule cell dendrites in the epl (Phillips et al., 1963; Mori and Takagi, 1978a, b). All of these excitatory inputs to the granule cells cause some degree of inhibition of mitral cell firing (Nakashima et al., 1978). This underscores the fact that the firing rate of mitral cells is closely coupled to the excitatory state of the granule cells. Thus, the inhibition of mitral cells during HDB potentiation is a strong indication that HDB terminals, directly or indirectly, excite granule cells.

\section{Synaptic mechanisms}

Both cholinergic and GABAergic neurons project to the MOB from the HDB (Brashear et al., 1986; Zaborszky et al., 1986); however, the effects of stimulating HDB cannot be attributed unambiguously to the reported effects of either of these transmitters. The GABAergic neurons presumably make inhibitory synapses. Postsynaptic inhibition by GABA is considered to result from an increase of conductance for chloride ion $\left(\mathrm{Cl}^{-}\right)$. Since the equilibrium potential for $\mathrm{Cl}^{-}$is near the resting membrane potential, activation of these synapses will not result in large extracellular currents (Rall and Shepherd, 1968). GABAergic transmission may involve a presynaptic receptor $\left(\mathrm{GABA}_{\mathrm{b}}\right)$ that blocks channels for $\mathrm{Ca}^{2+}$ (Bowery et al., 1980, 1987), but this mechanism will also not generate significant field potentials.

In the olfactory bulb there is strong binding of muscarinic ligands in the epl, $\mathrm{gcl}$, and ipl, with relatively little muscarinic binding in the gl (Hunt and Schmidt, 1978a; Blaha et al., 1984). In hippocampal pyramidal cells, application of muscarinic agonists causes inhibition of a voltage-dependent $\mathrm{K}^{+}$conductance, the M-current (Krnjevic et al., 1971; Krnjevic and Ropert, 1982; Cole and Nicoll, $1984 \mathrm{a}, \mathrm{b})$. The equilibrium potential of $\mathrm{K}^{+}$is usually near the resting membrane potential; hence, large extracellular currents are not usually generated by these channels. In addition, the time course reported for activation of M-channels is very slow, extending over 10-20 sec (Brown, 1983). Thus, this kind of muscarinic channel is unlikely to account for the observed field potentials.

Muscarinic receptors also occur on presynaptic terminals of afferent inputs and of intrinsic interneurons, where they inhibit the release of other transmitters (Krnjevic, 1981). The mechanisms of muscarinic presynaptic inhibition are not well understood; however, synapses onto terminals of axons cannot generate significant field potentials because there is insufficient intracellular cross section. Thus, these muscarinic effects also cannot account for the observed field potentials.

Receptors similar to peripheral nicotinic receptors are present in certain brain regions (Schwartz et al., 1982; Swanson et al., 1987). Nicotinic receptors for $\mathrm{ACh}$ would account for the observed field potentials, but the only evidence for such receptors in the olfactory bulb is the binding of $\alpha$-bungarotoxin (Hunt and Schmidt, 1978b; Blaha et al., 1984). This $\alpha$-bungarotoxin binding is, however, strictly confined to the gl and thus does not appear to be associated with the HDB field potentials reported here since these potentials arise from synaptic activity in much deeper parts of the bulb.

Thus, at the present time, we cannot definitely account for the currents underlying the $\mathrm{HDB}$ potential in terms of any previously suggested cholinergic or GABAergic membrane actions.

The transmitter(s) underlying the slowly developing facilitation that results in the potentiation wave is likewise uncertain. Muscarinic facilitation of the kind found in the hippocampal pyramidal cell (Cole and Nicoll, 1984a, b) can more plausibly account for the transition from passive to active response in the postulated inframitral cholinoceptive cell. As with the present effect, the muscarinic facilitation requires several seconds to develop. However, muscarinic facilitation decays with a time constant of 10-20 sec (Brown, 1983), unlike the present effect, which decays to half-amplitude in about $2 \mathrm{sec}$.

The slowly developing excitation could be caused by the release of a peptide cotransmitter from HDB terminals. Peptides have been colocalized with $\mathrm{ACh}$ in peripheral neurons; these peptides potentiate cholinergic actions during continuous stimulation but are not engaged by single shocks (Hökfelt et al., 1980; Lundberg, 1981; Lundberg and Hökfelt, 1983; Kawatani et al., 1985). The only putatively neuroactive peptide that has been colocalized with ChAT in HDB neurons is galanin (Melander et al., 1985), but there appears to be no information about the interaction between $\mathrm{AChE}$ and galanin on CNS neurons. 


\section{Functional implications}

Clearly, several plausible mechanisms acting independently or together could account for the potentiation, and the present experiments cannot distinguish among the possibilities. Stepping back from the issue of synaptic mechanisms, however, it is obvious from the present findings that inputs from forebrain magnocellular neurons (HDB) to a cortical target (MOB) have a potent effect when the parent neurons are activated at certain frequencies $(8-10 \mathrm{~Hz})$ for several seconds. The question arises whether such stimulus conditions are physiologically relevant; i.e., is this potentiation phenomenon likely to play a role in the normal functioning of the $\mathrm{HDB} \rightarrow \mathrm{MOB}$ projection? As there are no published reports of the discharge characteristics of HDB in behaving animals, it is not possible to answer this question directly. However, there is considerable circumstantial evidence to suggest that $\mathrm{HDB}$ neurons projecting to MOB may fire at such rates, specifically when the animal is engaged in exploratory sniffing. This evidence is described below.

Neurons in the medial septal nucleus (MS) maintain firing rates of $8-10 \mathrm{~Hz}$ for considerable periods in unanesthetized rats. Such periods are coincident with the occurrence of theta rhythm in the hippocampus (HC), and, indeed, there is a body of evidence suggesting that MS neurons play a pacemaker role in the generation of HC theta (Andersen et al., 1979). Komisaruk (1970) and Macrides et al. (1982) have shown that during exploratory sniffing behavior the olfactory bulb and $\mathrm{HC}$ are both dominated by theta rhythm. Macrides et al. (1982) also showed that the theta rhythms in the MOB and HC were often phase-locked for several seconds during bouts of exploratory sniffing. The olfactory bulb does not receive input from the medial septum, but it does receive a heavy projection from HDB, which is a subdivision of the same magnocellular forebrain complex as MS. It is reasonable to speculate, therefore, that HDB neurons, like their MS counterparts, function, in part, to pace theta rhythms in their cortical target, the MOB. Therefore, these neurons are likely to fire in the $8-10 \mathrm{~Hz}$ range during exploratory sniffing. The stimulation frequencies used to produce potentiation in the present experiments may thus be physiologically relevant. One important test of this hypothesis would be to record activities of single HDB neurons with antidromically confirmed projections to MOB in unanesthetized animals.

Assuming for the moment that HDB potentiation is physiologically relevant, it is important to ask what might be the functional significance of the HDB potentiation phenomenon and, also, whether potentiation of this kind might be a general property of hasal forebrain inputs to cortical targets. Unfortunately, very little is known about the functional physiology of these systems, and to date, there appear to have been no experiments comparable to those reported here on the projection from nucleus basalis to the neocortex. However, since these magnocellular forebrain systems show pronounced deterioration in Alzheimer's disease (Whitehouse et al., 1981, 1982) and since Alzheimer's patients have marked perturbations of memory and cognitive functions, it may be speculated that these systems are critical to cortical neural processing. Basal forebrain cholinergic projections to cortex are actually quite sparse in comparison with thalamocortical and corticocortical projections. HDB inputs to MOB are also quite sparse in comparison to afferents from the primary olfactory cortex. $\mathrm{HDB}$ cells in the mousc represent $3.5 \%$ of the neurons projecting to $\mathrm{MOB}$ (Carson, 1984). Thus, the profound inhibition of output neurons demonstrated here for one of these basal forebrain systems might suggest that, although they are anatomically sparse, magnocellular forebrain projections may have significant physiological impact on their cortical targets.

\section{References}

Andersen, P., H. B. Bland, T. Myhrer, and P. A. Schwartzkroin (1979) Septohippocampal pathway necessary for dentate theta production. Brain Res. 165: 13-22.

Blaha, G., W. Blair, W. T. Nickell, and M. T. Shipley (1984) Cholinergic $(\mathrm{CH})$ receptors in the rat olfactory bulb: Nicotinic $(\mathrm{N})$ and muscarinic (M) cholinergic receptors are segregated and coincide with acetylcholinesterase (AChE). Soc. Neurosci. Abstr. 10(2): 1183.

Bowery, N. G., D. R. Hill, A. L. Hudson, A. Doble, D. N. Middlemiss, J. Shaw, and M. Turnbull (1980) (-)Baclofen decreases neurotransmitter release in the mammalian CNS by an action at a novel GABA receptor. Nature 283: 92-94.

Bowery, N. G., A. L. Hudson, and G. W. Price (1987) GABA and $\mathrm{GABA}_{b}$ receptor distribution in the rat central nervous system. Neuroscience 20:365-383.

Brashear, H. R., L. Zaborszky, and L. Heimer (1986) Distribution of GABAergic and cholinergic neurons in the rat diagonal band. Neuroscience 17: 439-451.

Brown, D. A. (1983) Slow cholinergic excitation-A mechanism for increasing neuronal excitability. Trends Neurosci. 6: 302-307.

Carson, K. A. (1984) Quantitative localization of neurons projecting to the mouse main olfactory bulb. Brain Res. Bull. 12: 629-634.

Cole, A. E., and R. A. Nicoll (1984a) The pharmacology of cholinergic excitatory responses in hippocampal pyramidal cells. Brain Res. 305: 283-290.

Cole, A. E., and R. A. Nicoll (1984b) Characterization of a slow cholinergic post-synaptic potential recorded in vitro from rat hippocampal pyramidal cells. J. Physiol. (Lond.) 352: 173-188.

Coyle, J. T., D. L. Price, and M. R. DeLong (1983) Alzheimer's Disease-A disorder of cortical cholinergic innervation. Science 219: 1184-1190.

Davis, B. J., and F. Macrides (1981) The organization of centrifugal projections from the anterior olfactory nucleus, ventral hippocampal rudiment and piriform cortex to the main olfactory bulb in the hamster: An autoradiographic study. J. Comp. Neurol. 203: 477-495.

De Olmos, J., H. Hardy, and L. Heimer (1978) The afferent connections of the main and the accessory olfactory bulb formations in the rat: An experimental HRP-study. J. Comp. Neurol. 181: 213-244.

Dennis, B. J., and D. I. B. Keer (1976) Origins of olfactory bulb centrifugal fibres in the cat. Brain Res. 110: 593-600.

Hökfelt, T., O. Johansson, A. Ljungdahl, J. M. Lundberg, and M. Schultzberg (1980) Peptidergic neurons. Nature 284: 515-521.

Hunt, S., and J. Schmidt (1978a) Are mitral cells cholinergic? In Society for Neuroscience Symposia, Vol. 3, Aspects of Behavioral Neurobiology, J. A. Ferrendelli, ed., pp. 204-218, Society for Neuroscience, Bethesda, MD.

Hunt, S., and J. Schmidt (1978b) Some observations on the binding patterns of $\alpha$-bungarotoxin in the central nervous system of the rat. Brain Res. 157: 213-232.

Johnston, M. V., M. McKinney, and J. T. Coyle (1979) Evidence for a cholincrgic projection to neocortex from neurons in basal forebrain. Proc. Natl. Acad. Sci. USA 76: 5392-5396.

Kawatani, M., M Rutigliano, and W. C. DeGroat (1985) Depolarization and muscarinic excitation induced in a sympathetic ganglion by vasoactive intestinal polypeptide. Science 229: 878-881.

Kievit, J., and H. G. J. M. Kuypers .(1975) Basal forebrain and hypothalamic connections to frontal and parietal cortex in the rhesus monkey. Science 187: 660-662.

Kishi, K., K. Mori, and H. Ojima (1984) Distribution of local axon collaterals of mitral, displaced mitral, and tufted cells in the rabbit olfactory bulb. J. Comp. Neurol. 225: 511-526.

Komisaruk, B. R. (1970) Synchrony between limbic system theta activity and rhythmical behavior in rats. J. Comp. Physiol. Psychol. 70: 482-492.

Krnjevic, K. (1981) Acetylcholine as modulator of amino-acid-mediated synaptic transmission. In The Role of Peptides and Amino Acids as Neurotransmitters, B. J. Lombardini and A. D. Kenny, eds., pp. 127-141, Liss, New York.

Krnjevic, K., and N. Ropert (1982) Electrophysiological and phar- 
macological characteristics of facilitation of hippocampal population spikes by stimulation of the medial septum. Neuroscience $7: 2165$ 2183.

Krnjevic, K., R. Pumain, and L. Renaud (1971) The mechanism of action of acetylcholine in the cerebral cortex. J. Physiol. (Lond.) 215: $247-268$.

Lundberg, J. M. (1981) Evidence for coexistence of vasoactive intestinal polypeptide (VIP) and acetylcholine in neurons of cat exocrine glands. Morphological, biochemical and functional studies. Acta Physiol. Scand. Suppl. 496: 1-57.

Lundberg, J. M., and T. Hökfelt (1983) Coexistence of peptides and classical neurotransmitters. TINS 6: 325-333.

Macrides, F., and B. J. Davis (1983) The olfactory bulb. In Chemical Neuroanatomy, P. C. Emson, ed., pp. 391-426, Raven, New York.

Macrides, F., B. J. Davis, W. M. Youngs, N. S. Nadi, and F. L. Margolis (1981) Cholinergic and catecholaminergic afferents to the olfactory bulb in the hamster: A neuroanatomical, biochemical and histochemical investigation. J. Comp. Neurol. 203: 495-514.

Macrides, F., H. B. Eichenbaum, and W. B. Forbes (1982) Temporal relationship between sniffing and the limbic rhythm during odor discrimination reversal learning. J. Neurosci. 2: 1705-1717.

McLean, J. H., and M. T. Shipley (1987) Serotonergic afferents to the rat olfactory bulb: I. Origins and laminar specificity of serotonergic inputs in the adult rat. J. Neurosci. 7: 3016-3028.

McLean, J. H., W. T. Nickell, and M. T. Shipley (1986) Afferent connections to the horizontal limb of the diagonal band. Soc. Neurosci. Abstr. 12: 351.

Melander, T., W. A. Staines, T. Hökfelt, A. Rokaeus, F. Eckenstein, P. M. Salvatera, and B. H. Wainer (1985) Galanin-like immunoreactivity in cholinergic neurons of the septum-basal forebrain complex projecting to the hippocampus. Brain Res. 360: 130-138.

Mesulam, M.-M., and G. W. Van Hoesen (1976) Acetylcholinesteraserich projections from the basal forebrain of the rhesus monkey to neocortex. Brain Res. 109: 152-157.

Mesulam, M.-M., E. J. Mufson, A. I. Levey, and B. H. Wainer (1983a) Cholinergic innervation of cortex by the basal forebrain: Cytochemistry and cortical connections of the septal area, diagonal band nuclei, nuclcus basalis (substantia innominata), and hypothalamus in the rhesus monkey. J. Comp. Neurol. 214: 170-197.

Mesulam, M.-M., E. J. Mufson, B. H. Wainer, and A. I. Levey (1983b) Central cholinergic pathways in the rat: An overview based on an alternative nomenclature (Ch1-Ch6). Neuroscience 10: 1185-1201.

Mori, K., and S. F. Takagi (1978a) Activation and inhibition of olfactory bulb neurones by anterior commissure volleys in the rabbit. $\mathrm{J}$. Physiol. (Lond.) 279: 589-604.

Mori, K., and S. F. Takagi (1978b) An intracellular study of dendrodendritic inhibitory synapses on mitral cells in the rabbit olfactory bulb. J. Physiol. (Lond.) 279: 569-588.

Nakashima, M., K. Mori, and S. F. Takagi (1978) Centrifugal influence on olfactory bulb activity in the rabbit. Brain Res. 154: 301316.

Nickcll, W. T., and M. T. Shiplcy (1988) Two anatomically specific classes of candidate cholinoceptive neurons in the rat olfactory bulb. J. Neurosci. 8: 4482-4491.

Orono, E., E. C. Rainer, and J. W. Scott (1984) Dendritic and axonal organization of mitral and tufted cells in the rat olfactory bulb. J. Comp. Neurol. 226: 346-356.

Phillips, C. G., T. P. S. Powell, and G. M. Shepherd (1963) Responses of mitral cells to stimulation of the lateral olfactory tract in the rabbit. J. Physiol. (Lond) 168: 65-88.

Price, J. L., and T. P. S. Powell (1970) An experimental study of the origin and the course of the centrifugal fibres to the olfactory bulb in the rat. J. Anat, (Lond.) 107: 215-237.

Rall, W., and G. M. Shepherd (1968) Theoretical reconstruction of field potentials and dendro-dendritic synaptic interactions in olfactory bulb. J. Neurophysiol. 31: 884-915.

Rye, D. B., B. H. Wainer, M.-M. Mesulam, E. J. Mufson, and C. B. Saper (1984) Cortical projections arising from the basal forebrain: A study of cholinergic and non-cholinergic components employing combined retrograde tracing and immunohistochemical localization of choline acetyltransferase. Neuroscience 13: 627-643.

Schneider, S. P., and F. Macrides (1978) Laminar distribution of interneurons in the main olfactory bulb of the adult hamster. Brain Res. Bull. 3: 73-82.

Schwartz, R. D., R. McGee, Jr., and K. Kellar (1982) Nicotinic cholinergic receptors labelled by $\left[{ }^{3} \mathrm{H}\right]$-acetylcholine in rat brain. Mol. Pharmacol. 22: 56-62.

Scott, J. W. (1981) Electrophysiological identification of mitral and tufted cells and distributions of their axons in olfactory system of the rat. J. Neurophysiol. 46: 918-931.

Shepherd, G. M. (1972) Synaptic organization of the mammalian olfactory bulb. Physiol. Rev. 52: 864-917.

Shipley, M. T., and G. D. Adamek (1984) The connections of the mouse olfactory bulb: A study using orthograde and retrograde transport of wheat germ agglutinin conjugated to horseradish peroxidase. Brain Res. Bull. 12: 669-688.

Shipley, M. T., W. T. Nickell, and J. H. McLean (1986) Organization of afferents from the nucleus of the diagonal band to the olfactory bulb. Chem. Senses 11: 663 .

Shute, C. C. D., and P. R. Lewis (1967) The ascending cholinergic reticular system: Neocortical olfactory and subcortical projections. Brain 90: 497-520.

Swanson, L. W., D. M. Simmons, P. J. Whiting, and J. Lindstrom (1987) Immunohistochemical localization of neuronal nicotinic receptors in the rodent central nervous system. J. Neurosci. 7: 33343342.

Wainer, B. H., A. I. Levey, D. B. Rye, M.-M. Mesulam, and E. J. Mufson (1985) Cholinergic and non-cholinergic septo-hippocampal pathways. Neurosci. Lett. 54: 45-52.

Whitehouse, P. J., D. L. Price, A. W. Clark, J. T. Coyle, and M. R. DeLong (1981) Alzheimer's Disease: Evidence for selective loss of cholinergic neurons in nucleus basalis. Ann. Neurol. 10: 122-126.

Whitehouse, P. J., D. L. Price, R. G. Struble, A. W. Clark, J. T. Coyle, and M. R. DeLong (1982) Alzheimer's Disease and senile dementia: Loss of neurons in the basal forebrain. Science 215: 1237-1239.

Zaborszky, L., J. Carlsen, H. R. Brashear, and L. Heimer (1986) Cholincrgic and GABAcrgic afferents to the olfactory bulb in the rat with special emphasis on the projection from the horizontal limb of the diagonal band. J. Comp. Neurol. 243: 488-509. 